\title{
A Clinical Analysis of Extrapulmonary Complications in Novel Coronavirus Pneumonia Patients
}

This article was published in the following Dove Press journal: International Journal of General Medicine

\author{
Bo-Wen Sun ${ }^{1} *$ \\ Min Zhang ${ }^{1}, *$ \\ Ping-Chao Wang ${ }^{2}$ \\ Jiang-Tao Song ${ }^{3}$
}

'Department of Respiratory Medicine, Heilongjiang Provincial Hospital, Harbin Institute of Technology, Harbin, 150036, People's Republic of China; ${ }^{2}$ Department of Critical Care Medicine, People's Hospital of Hanchuan, Hanchuan, 43I600, People's Republic of China; ${ }^{3}$ Department of Orthopedics, People's Hospital of Hanchuan, Hanchuan,

431600, People's Republic of China

*These authors contributed equally to this work
Correspondence: Ping-Chao Wang Department of Critical Care Medicine, People's Hospital of Hanchuan, No. I Of Peoples Avenue, Hanchuan, 431600, People's Republic of China Tel +86/3508692696

Email wamgpimgchao@2Icn.com

Jiang-Tao Song

Department of Orthopedics, People's

Hospital of Hanchuan, No. I Of Peoples

Avenue, Hanchuan, 431600, People's

Republic of China

Tel +861342992I750

Email somgjiamgtao@I63.com
Objective: This study aimed to investigate the clinical manifestation and treatment effects of extrapulmonary complications in cases of novel coronavirus pneumonia.

Methods: The clinical data of patients with novel coronavirus pneumonia who were admitted to Hanchuan People's Hospital between January and March 2020 were retrospectively analyzed, and the clinical characteristics, laboratory test results, and treatment pathways of patients with extrapulmonary complications were analyzed and summarized.

Results: Of the 500 patients in this study, 97 patients with a history of chronic diseases were excluded, and 152 patients had extrapulmonary complications. Common extrapulmonary syndromes: 98 patients $(64.47 \%)$ suffered from digestive system involvement; 43 patients (28.29\%) suffered from cardiovascular system damage; 32 patients $(21.05 \%)$ had urinary system damage; 25 patients (16.45\%) had nervous system damage; and 30 patients $(19.74 \%)$ had more than two kinds of system damage. In all cases, these patients were treated with comprehensive measures, and effective outcomes were achieved.

Conclusion: According to the clinical characteristics and laboratory test results of this sample group, early evaluation of patients with extrapulmonary complications and timely symptomatic treatment can effectively improve outcomes of pneumonia treatment, accelerate the alleviation of symptoms, and improve patients' condition.

Keywords: novel coronavirus pneumonia, clinical characteristics, laboratory test, extrapulmonary complications, curative effect

\section{Introduction}

The novel coronavirus pneumonia is a form of viral pneumonia that was first discovered in China in late 2019. Novel coronavirus pneumonia is a class $\mathrm{B}$ infectious disease and is managed according to class $\mathrm{A}$ in China. With the development of the epidemic, the disease has spread to almost every country in the world. The number of patients and deaths is increasing day by day, causing a global pandemic. ${ }^{1-3}$ As of 24:00 on April 30, there were 2,016,555 unrecovered confirmed cases, 3,235,409 cumulative confirmed cases, 227,823 deaths, and 991,031 recovered cases globally (http://www.nhc.gov.cn/). This epidemic poses a huge threat to the lives of the people of China and the global population, and it is having a serious impact on global economic development. On February 11, 2020, the World Health Organization officially named the disease coronavirus disease 2019 (COVID-19). ${ }^{4,5}$ The novel coronavirus is the pathogen of the disease, ${ }^{6}$ and it is highly infectious and pathogenic. The disease primarily causes lung damage, but 
it also affects multiple organs, especially in the digestive and cardiovascular systems. ${ }^{7}$ If a patient's extrapulmonary complications are not addressed early enough, the delay can severely impact the overall treatment effect and prognosis. However, to date, novel coronavirus pneumonia patients with extrapulmonary complications have only been studied to a limited extent. In the current study, we analyzed 500 patients who were admitted to Hanchuan People's Hospital and were treated by the hospital's supporting medical team, with a focus on patients with extrapulmonary complications, to provide a scientific basis for clinical diagnosis and treatment.

\section{Information and Methods}

\section{General Information}

The clinical data of 500 patients with novel coronavirus pneumonia (meeting the diagnostic criteria of the Diagnosis and Treatment Protocol for Novel Coronavirus Pneumonia [Trial Version 7] $]^{6}$, who were admitted to Hanchuan People's Hospital between January and March 2020, were retrospectively analyzed. Among these 500 individuals, 97 patients with a chronic history of cardiovascular or cerebrovascular diseases, hepatitis, cirrhosis, or renal insufficiency were excluded, and 152 among the remaining 403 patients (37.72\%) had extrapulmonary complications. The age range of the patients was 23-89 years, and their average age was $45 \pm 0.5$ years. Seventy-eight (51.32\%) of the patients were males and 74 (46.68\%) were female. The length of hospital stay ranged between 6 and 40 days, with an average of $15 \pm 0.5$ days. I confirm that I have read the Editorial Policy pages. This study was conducted with approval from the Ethics Committee of Hanchuan People's Hospital. This study was conducted in accordance with the declaration of Helsinki. Written informed consent was obtained from all participants.

\section{Methods}

Novel coronavirus nucleic acids were detected in nasopharyngeal swabs or in sputum or other respiratory secretions by reverse transcription polymerase chain reaction upon admission of each patient. Novel coronavirusspecific antibody tests were positive in some patients. For this study, we analyzed and summarized the clinical characteristics, laboratory test results, and treatment pathways of patients with extrapulmonary complications. Basic treatment: Symptomatic support treatments such as oxygen inhalation and anti-inflammatory and anti-virus medications were given, and then the therapeutic effects were observed. According to each patient's condition, the patients were given anti-infection, gastric mucosa protection, myocardial nutrition, heart failure correction, liver protection, and kidney protection treatment measures among others.

\section{Inclusion Criteria for Subjects}

Inclusion criteria:The symptoms of patients with digestive system injury include poor appetite, abdominal distension, diarrhea, nausea, vomiting and other gastrointestinal symptoms, accompanied by abnormal liver function. Abnormal liver function refers to the increased ALT/ AST/DBiL/IBiL/TBiL beyond the normal range.

The manifestations of patients with cardiovascular system injury included palpitation, chest distress, and chest pain, accompanied by elevated myocardial enzymes or electrocardiogram (ECG) changes.

The manifestations of renal injury were oliguria or hematuria, accompanied by renal dysfunction. Renal dysfunction refers to an increase in creatinine or urea nitrogen beyond the normal range.

Those of patients with nervous system injury included dizziness, headache, disturbance of consciousness, and convulsions, with or without abnormal electroencephalogram or cerebrospinal fluid test results.

Exclusion criteria: the patient had a history of cardiovascular and cerebrovascular diseases, hepatitis, liver cirrhosis, renal insufficiency and other chronic diseases.

\section{Efficacy Evaluation for Pneumonia}

\section{Treatment}

Obvious effect: the respiratory symptoms disappeared in the patients, and the pulmonary lesions disappeared completely or mostly in the CT scan of the lungs. Effective: the respiratory symptoms of the patients disappeared, and the small range of pulmonary lesions could be seen on lung CT. Invalid: the patient's respiratory symptoms did not improve, lung $\mathrm{CT}$ showed no change or exacerbation of lung lesions.

\section{Efficacy Evaluation for Treatment of Extrapulmonary Complications}

Cure: the clinical symptoms of the patient's extrapulmonary complications disappeared, and the corresponding laboratory test results returned to the normal range from abnormal; Improvement: the clinical symptoms of patients with 
extrapulmonary complications were reduced or disappeared, and the corresponding laboratory test results were decreased, but not within the normal range; Invalid: no relief in clinical symptoms and no improvement in laboratory test results.

\section{Statistical Analysis}

The data were analyzed using statistical software SPSS 17.0. Count data were expressed as percentage values (\%) and compared using the Chi-square test. Measurement data were expressed as mean \pm standard deviation $(\mathrm{x} \pm \mathrm{SD})$, inter-group comparison was conducted using analysis of variance, and pairwise comparison was conducted using $\mathrm{Q}$ testing. $\mathrm{P}<0.05$ was considered statistically significant.

\section{Results}

\section{Composition of Extrapulmonary Complications}

The observed incidence rates of different extrapulmonary complications of novel coronavirus pneumonia, from most to least frequent, were: digestive system involvement, cardiovascular system damage, urinary system damage, and nervous system damage. Some of the patients in our sample had two or more of these complications. There was no significant difference in the ratios of cases of various extrapulmonary complications in male and female patients. However, there was a statistically significant difference in the age of patients with various extrapulmonary complications; in particular, cardiovascular system damage was more common among the older members of the population (Table 1).

\section{Comparison of Treatment Effects}

In this study, the effects of treatment for patients with extrapulmonary complications were not as effective as for patients without complications, but they were still superior to those of patients with chronic diseases at a statistically significant level (Table 2). The curative effects of treatment decreased significantly as patient age increased, and the different was statistically significant. However, "there was no significant difference in curative effects between male and female patients among patients in each age group (Table 3 ).

The difference in the clinical curative effects of the COVID-19 patients with different extrapulmonary complications was not statistically significant (Table 4).

\section{Discussion}

Novel coronavirus pneumonia is an infectious disease caused by a novel coronavirus that mainly manifests as a respiratory tract infection. It has the characteristics of high infectivity and high pathogenicity. ${ }^{8}$ At present, the source of the virus is not clear; however, research has revealed that its homology with severe acute respiratory syndrome coronavirus in bats is over $85 \%$. Additionally, studies have confirmed that the routes of transmission are mainly respiratory droplets and close contact; in most patients with confirmed cases, the definite source of infection can be traced back to these routes. ${ }^{9}$ The virus incubation period is typically between 10 and 14 days, but it can be as long as 24 days. $^{10-13}$ The main clinical manifestations are fever, cough, dyspnea, and other respiratory symptoms; most patients also have general symptoms such as asthenia and poor appetite. ${ }^{7}$ Lung computed tomography results mainly show multiple small patchy shadows and interstitial changes. ${ }^{14,15}$ Early routine blood tests show that white blood cell count does not increase; meanwhile, a progressive decrease in lymphocyte count may indicate a poor prognosis. ${ }^{16}$ Depending on a patient's epidemiological history, clinical manifestations, and physical and chemical examination results, it is often not

Table I Incidence of Extrapulmonary Complications in I52 COVID-19 Patients

\begin{tabular}{|l|l|l|l|l|l|}
\hline Damaged System & The Number of Cases & Proportion (\%) & \multicolumn{2}{|l|}{ The number of Gender Cases $^{\mathbf{a}}$} & Average Age (Years Old) $^{\mathbf{b}}$ \\
\hline Digestive system & 98 & 64.47 & $\begin{array}{l}\text { Male } \\
\text { Female }\end{array}$ & $\begin{array}{l}58 \\
40\end{array}$ & $43 \pm 0.5$ \\
\hline Cardiovascular system & 43 & 28.29 & $\begin{array}{l}\text { Male } \\
\text { Female }\end{array}$ & $\begin{array}{l}25 \\
18\end{array}$ & $56 \pm 0.5$ \\
\hline Urinary system & 32 & 21.05 & $\begin{array}{l}\text { Male } \\
\text { Female }\end{array}$ & 15 & $45 \pm 0.5$ \\
\hline Nervous system & 25 & 16.45 & $\begin{array}{l}\text { Male } \\
\text { Female }\end{array}$ & $\begin{array}{l}12 \\
13\end{array}$ & $39 \pm 0.5$ \\
\hline
\end{tabular}

Notes: ${ }^{a}$ There is no significant difference in the ratio of male to female in various extrapulmonary complications $\mathrm{X}^{2}=2.193$, $\mathrm{P}>0.05 ;{ }^{\mathrm{b}}$ The difference in age among patients with various extrapulmonary complications was statistically significant $\mathrm{F}=67.382, \mathrm{P}<0.05$. 
Table 2 Comparison of Clinical Curative Effect Among Patients without Complications, Patients with Extrapulmonary Complications and Patients with Chronic Diseases

\begin{tabular}{|l|l|l|l|l|l|l|l|}
\hline & $\begin{array}{l}\text { Proportion } \\
\text { (\%) }\end{array}$ & $\begin{array}{l}\text { Number of } \\
\text { Patients } \\
\text { with } \\
\text { Excellent } \\
\text { Effect }\end{array}$ & $\begin{array}{l}\text { Proportion } \\
\text { (\%) }\end{array}$ & $\begin{array}{l}\text { Number of } \\
\text { Patients with } \\
\text { Effective } \\
\text { Outcomes }\end{array}$ & $\begin{array}{l}\text { Proportion } \\
\text { (\%) }\end{array}$ & $\begin{array}{l}\text { Number of } \\
\text { Patients with } \\
\text { Ineffective } \\
\text { Outcome }\end{array}$ & $\begin{array}{l}\text { Proportion } \\
\text { (\%) }\end{array}$ \\
\hline $\begin{array}{l}\text { Patients without } \\
\text { complications }\end{array}$ & 251 & 198 & 78.88 & 53 & 21.12 & 0 & 0 \\
\hline $\begin{array}{l}\text { Patients with } \\
\text { complications }\end{array}$ & 152 & 93 & 61.18 & 55 & 36.18 & 4 & 2.63 \\
\hline $\begin{array}{l}\text { Patients with chronic } \\
\text { disease }\end{array}$ & 97 & 38 & 39.18 & 44 & 45.36 & 15 & 15.46 \\
\hline
\end{tabular}

Note: Comparison among groups: $\mathrm{X}^{2}=73.795, \mathrm{P}<0.05$.

Table 3 Comparison of Age and Gender Among Patients with Extrapulmonary Complications in Different Therapeutic Groups

\begin{tabular}{|c|c|c|c|c|c|c|}
\hline \multirow[b]{2}{*}{ Excellent } & \multirow{2}{*}{$\begin{array}{l}\text { The Number of Cases } \\
93\end{array}$} & \multirow{2}{*}{$\begin{array}{l}\text { Proportion (\%) } \\
61.18\end{array}$} & \multirow{2}{*}{$\begin{array}{l}\text { Average Age }{ }^{\mathrm{a}} \text { (Years Old) } \\
34 \pm 0.5\end{array}$} & \multicolumn{2}{|c|}{$\begin{array}{l}\text { The Number } \\
\text { of Gender } \\
\text { Cases }^{b}\end{array}$} & \multirow{2}{*}{$\begin{array}{l}\text { Ratio of Male-to-Female(\%) } \\
53.76 \\
46.24 \\
\end{array}$} \\
\hline & & & & $\begin{array}{l}\text { Male } \\
\text { Female }\end{array}$ & $\begin{array}{l}50 \\
43\end{array}$ & \\
\hline Effective & 55 & 36.18 & $47 \pm 0.5$ & $\begin{array}{l}\text { Male } \\
\text { Female }\end{array}$ & $\begin{array}{l}25 \\
30\end{array}$ & $\begin{array}{l}45.45 \\
54.55\end{array}$ \\
\hline Ineffective & 4 & 2.63 & $65 \pm 0.5$ & $\begin{array}{l}\text { Male } \\
\text { Female }\end{array}$ & $\begin{array}{l}3 \\
1\end{array}$ & $\begin{array}{l}0.75 \\
0.25\end{array}$ \\
\hline
\end{tabular}

Notes: ${ }^{a}$ There is statistical difference in age among all treatment groups $(\mathrm{F}=\mathrm{I} .50 \mathrm{I}, \mathrm{P}<0.05)$; ${ }^{\mathrm{b}}$ There is no statistical difference among all curative effect groups $\left(\mathrm{X}^{2}=\mathrm{I} .877, \mathrm{P}>0.05\right)$.

difficult to conduct preliminary clinical screening; however, instances of misdiagnosis or missed diagnosis are likely to occur in patients who have extrapulmonary manifestations.

Table 4 Comparison of Clinical Curative Effect of the COVID19 Patients with Different Extrapulmonary Complications

\begin{tabular}{|l|l|l|l|l|}
\hline & $\begin{array}{l}\text { Number } \\
\text { of Total } \\
\text { Cases }\end{array}$ & Cured & Improved & Ineffective \\
\hline $\begin{array}{l}\text { Digestive } \\
\text { system damage }\end{array}$ & 98 & 79 & 15 & 4 \\
\hline $\begin{array}{l}\text { Cardiovascular } \\
\text { system damage }\end{array}$ & 43 & 28 & 11 & 4 \\
\hline $\begin{array}{l}\text { Urinary system } \\
\text { damage }\end{array}$ & 32 & 19 & 10 & 3 \\
\hline $\begin{array}{l}\text { Nervous } \\
\text { system damage }\end{array}$ & 25 & 20 & 4 & 1 \\
\hline
\end{tabular}

Notes: The difference in the clinical curative effect of COVID-19 patients with different extrapulmonary complications was not statistically significant $\left(X^{2}=8.154, P<0.05\right)$.
Especially when these are the first symptoms, the disease can be complicated, and careful analysis by clinicians is needed.

The findings of this study reveal that, in addition to respiratory symptoms, novel coronavirus pneumonia has a high incidence of extrapulmonary complications. The most common of these is digestive system involvement, followed by cardiovascular system damage and urinary system damage, while the occurrence rate of damage to the nervous system is relatively low. In the present study, 500 cases were retrospectively analyzed. According to the results, 98 (19.6\%) of the sample patients without a history of related basic diseases showed poor appetite, and their blood biochemical tests indicated that their transaminase levels were increased. Patients with abnormal myocardial zymogram and ECG changes accounted for $8.6 \%$ of the sample; these findings were more common in elderly patients. The abnormal cardiac enzyme profile is the elevated cardiac enzyme (AST/LDH/CK). Finally, the incidence rates of renal dysfunction and neurological 
symptoms were $6.4 \%$ and $5 \%$, respectively. To date, no studies have reported a clear pathogenesis for the virus; it has not been excluded that it is related to immune factors. The findings of the present study suggest that the prognosis of patients with extrapulmonary complications is poorer than for those without complications but significantly superior to that of patients with previous underlying diseases. In addition, age has a certain impact on clinical curative effects; in general, curative effects were observed to be affected by an increase in age. However, after active antiviral and symptomatic support treatment, most patients had a good prognosis, and the overall rate of curing extrapulmonary complications was high. It was also observed that very few patients had sequelae.

\section{Conclusion}

In the present study, confirmed novel coronavirus pneumonia patients were retrospectively analyzed from the perspective of extrapulmonary complications. The results revealed a high incidence of extrapulmonary manifestations and a direct impact of the curative effects for extrapulmonary complications on those for pneumonia. These findings indicate that clinicians should pay attention to the interference factors presented by complications in differentiation from novel coronavirus pneumonia from other diseases. In addition, close monitoring of the clinical manifestations and laboratory tests of patients, early detection of complications, and active symptomatic treatment all play key roles in improving the symptoms and prognosis of patients with COVID-19.

\section{Disclosure}

The authors report no conflicts of interest in this work.

\section{References}

1. Wuhan Municipal Health Commission. Wuhan Municipal Health Commission on the current situation of pneumonia epidemic in our city.Circulars [EB/OL]. 2020. Available from: http://wjw.wuhan.gov. $\mathrm{cn} /$ front/web/showDetail/2019123108989. Accessed January 28, 2020
2. Bogoch II, Watts A, Thomas-Bachli A, Huber C, Kraemer MUG, Khan K. Pneumonia of unknown aetiology in Wuhan, China: potential for international spread via commercial air travel. J Travel Med. 2020;7:aaa008.

3. Munster VJ, Koopmans M, van Doremalen N, van Riel D, de Wit E, Novel Coronavirus A. Emerging in China - Key Questions for Impact Assessment. N Engl J Med. 2020;382:692-694.

4. Zhu N, Zhang D, Wang W, et al. China Novel Coronavirus Investigating and Research Team. A Novel Coronavirus from Patients with Pneumonia in China, 2019. $N$ Engl $J$ Med. 2020;382:727-733.

5. WHO. WHO Director-General's Remarks at the Media Briefing on 2019-nCoV on 11 February 2020; 2020.

6. Li Q, Guan X, Wu P, et al. Early transmission dynamics in wuhan, china, of novel coronavirus-infected pneumonia. $N$ Engl $J$ Med. 2020;382:1199-1207.

7. Novel Coronavirus Pneumonia Treatment Protocol, Seventh Edition. national health and wellness commission of the people's republic of China. 2020. Available from: http://www.nhc.gov.cn/yzygi/s7653p/ 202001/4294563ed35b43209b31739bd0785e67.shtml. Accessed January 28, 2020

8. Jin Y, Cai L, Cheng Z, et al. Pneumonia prevention and treatment of novel coronavirus infection in Central South Hospital of Wuhan University. Rapid recommendations for diagnosis and treatment of pneumonia associated with novel coronavirus (2019-nCoV) infection (standard version). PLA J Med. 2020;45:1-20.

9. Li YZ, He H, Chen Q. Progress in the study of novel coronavirus pneumonia. J Trop Med. 2020;20:581-586.

10. Lauer SA, Grantz KH, Bi Q, et al. The Incubation Period of Coronavirus Disease 2019 (COVID-19) From Publicly Reported Confirmed Cases: estimation and Application. Ann Intern Med. 2020;172:577-582.

11. Huang C, Wang Y, Li X, et al. Clinical features of patients infected with 2019 novel coronavirus in Wuhan, China. Lancet. 2020;395:497-506.

12. Lu R, Zhao X, Li J, et al. Genomic characterisation and epidemiology of 2019 novel coronavirus: implications for virus origins and receptor binding. Lancet. 2020;395:565-574.

13. Phan LT, Nguyen TV, Luong QC, et al. Importation and Human-toHuman Transmission of a Novel Coronavirus in Vietnam. $N$ Engl J Med. 2020;382(9):872-874.

14. Tang GX, Li CH, Liu XY, et al. Clinical and CT manifestations of novel coronavirus pneumonia. Chin $J$ Respir Crit Care Nur. 2020;19:161-165.

15. Diao KY, Han PL, Pang T, et al. High-resolution CT of the chest in new coronavirus pneumonia: performance and changes. Chin J Respir Crit Care Nur. 2020;19:166-171.

16. Wang Y, Zhao $\mathrm{CC}, \mathrm{Gu} \mathrm{Y}$, et al. 80 cases of pneumonia in patients with novel coronavirus infection. Clin Blood Transfus Test. 2020;22:360-365.
International Journal of General Medicine

\section{Publish your work in this journal}

The International Journal of General Medicine is an international, peer-reviewed open-access journal that focuses on general and internal medicine, pathogenesis, epidemiology, diagnosis, monitoring and treatment protocols. The journal is characterized by the rapid reporting of reviews, original research and clinical studies across all disease areas. The manuscript management system is completely online and includes a very quick and fair peer-review system, which is all easy to use. Visit http://www.dovepress.com/ testimonials.php to read real quotes from published authors. 